\title{
ANÁLISE DOS REGISTROS DE ENTREVISTA INICIAL FONOAUDIOLÓGICA EM SUJEITOS COM DIAGNÓSTICO DE GAGUEIRA
}

\author{
Tatiana Maria Corrêa Cavalcanti* \\ Nadia Pereira Gonçalves de Azevedo**
}

\begin{abstract}
RESUMO: Este estudo visa a investigar a gagueira na clínica fonoaudiológica e os registros da anamnese, em pacientes diagnosticados como gagos. A análise foi realizada a partir do estudo das pastas de 40 pacientes. Procurou-se identificar o perfil desses sujeitos e discuti-lo a partir das categorias: etiologia da gagueira; auto-imagem; ativação emocional; contato visual e o uso de estratégias. Os resultados obtidos revelaram que $17,5 \%$ dos participantes relacionam a causa da gagueira ao uso dos discursos autoritários dos adultos; $15 \%$ à hipótese genética; 7,5\% a algum trauma sofrido na infância; 45\% apresentam imagem estigmatizada de falante; $40 \%$ apresentam piora da gagueira em situações de estresse; $35 \%$ apresentam alteração no contato visual e 32,5\% revelaram fazer uso de estratégias para adiar sua gagueira.
\end{abstract}

PALAVRAS-CHAVE: Gagueira - Discurso - Anamnese

ABSTRACT: This present study aims to investigate the stuttering in a speach therapy clinic and the registers of anamnese, in diagnosed stutterer patients. The analysis was carried out from the study of 40 patient folders. It was attempted to identify the profile of these subjects and discuss it considering the following categories: etiology of the stuttering; self-image; emotional activation; visual contact, and the use of strategies. Results showed that $17.5 \%$ of the subjects had related the cause from stuttering to the use of adult's authoritarian speaking; $15 \%$ to genetic hypothesis; $7.5 \%$ to any childhood trauma; $45 \%$ have stigmatized image of speaker; $40 \%$ of the subjects showed an increase of stuttering in stress situations; $35 \%$ showed alterations in visual contacts, and $32.5 \%$ revealed that they use some strategy to late their stuttering.

KEYWORDS: Stuttering - Speech-anamneses

\section{CONSIDERAÇÕES INICIAIS}

A Clínica Manuel de Freitas Limeira, da Unicap, em seu setor de Fonoaudiologia, apresenta uma demanda considerável de sujeitos com queixa de gagueira. Entre esses, adolescentes, adultos e pais de crianças ditas gagas, que nos procuram em busca de terapia e aconselhamento. O perfil desses sujeitos e do trabalho fonoaudiológico realizado com eles ainda não existe à disposição dos professores.

Este trabalho pretende realizar uma análise dos registros de anamnese dos pacientes diagnosticados como gagos da clínica da Unicap, identificando as possibilidades etiológicas afirmadas pelos sujeitos-gagos e o relato da queixa de gagueira pelo paciente e/ou responsável por este. Além disso, busca analisar os

*Mestranda. Universidade Católica de Pernambuco. E-mail: tatianac.cavalcanti@hotmail.com.

**Doutora. Universidade Católica de Pernambuco. E-mail: nadiaazevedo@terra.com.br. 
procedimentos avaliativos dos pacientes diagnosticados como gagos da clínica da Unicap, procurando identificar as estratégias utilizadas pelos sujeitos-gagos para evitar ou adiar a gagueira e a previsão do erro na gagueira.

Desta forma, este trabalho procurará apresentar a visão de diferentes autores sobre a gagueira, apontando para a possibilidade discursiva como via de acesso aos sujeitos-gagos. Em seguida, serão discutidos os resultados encontrados na pesquisa.

\section{ENTRE O SUJEITO E OS DISCURSOS: UMA HISTÓRIA DA GAGUEIRA}

A maioria dos estudos sobre a gagueira se caracteriza por abordagens positivistas do problema, que a descrevem pela sua manifestação externa, observável de imediato, ou seja, pela sua aparência. Esta aparência externa, observada no indivíduo, cria uma representação da gagueira, que acaba se transformando em conceito. (FRIEDMAN, 1986).

Existem poucos estudos que contemplem a gagueira sob o ponto de vista de uma teoria de linguagem. Todas as teorias, evidentemente, apresentam contribuições à clínica fonoaudiológica, na medida em que, de seus lugares teóricos, operam alguma forma de circunscrição da gagueira. Por não partirem de uma teoria de linguagem, essas abordagens, naturalmente fiéis à fundamentação teórica em que se apóiam, deixam escapar a linguagem e, com ela, excluem o sujeito, uma vez que ambos se encontram indissoluvelmente atrelados, pois sujeito e linguagem se constituem mutuamente.

Andrade e Bohnen (apud AZEVEDO, 2006) apresentam uma visão organicista da gagueira, apresentando outros componentes que poderiam estar relacionados à sua origem, como os hereditários, biológicos, psicológicos, linguísticos e sociais, ficando clara em suas pesquisas uma forte sustentação biológica, com uma proposta avaliativa e terapêutica quantitativa. Nessa perspectiva, sujeito e linguagem são excluídos. Em seus lugares, está a gagueira, o corpo, a quantidade de sílabas gaguejadas, um protocolo de risco.

Diante do que foi relatado acima, podemos afirmar que as publicações em relação à gagueira requerem mais estudos que priorizem a linguagem e o sujeito em sua abordagem. Há, ainda, muitos trabalhos que apresentam o modelo organicista/quantitativo como foco, porém há outros que, fundamentados na Psicanálise e no Materialismo Histórico, como os representados por Cunha; Tassinari e Friedman, respectivamente, mostram uma perspectiva subjetiva de compreensão da gagueira e apontam para possibilidades terapêuticas em relação aos sujeitos-gagos (AZEVEDO, 2006).

Diante de tanto mistério sobre a origem da gagueira, vários pesquisadores de diversas tendências sentiram-se seduzidos em explorar esse enigma. Van Riper (1972, p. 1), um dos maiores estudiosos e clínicos da gagueira do século XX, afirma: "a gagueira tem sido nomeada como mistérios, charada, é mais do que isso: gagueira é como um quebra-cabeça complicado, multidimensionado, com muitas peças ainda faltando". Como podemos ver, o autor relaciona a gagueira ao nível articulatório, tendo comprometimento no ato motor.

$\mathrm{Na}$ área da psicologia social, Friedman (1986) situa a origem da gagueira na primeira infância, quando a criança passa por uma fase de gagueira natural e os pais apontam essa disfluência. Podemos fazer uma analogia da gagueira fisiológica ao ato motor. Quando a criança começa a andar, cai frequentemente, o que, geralmente, é 
compreendido pelos pais como parte integrante do processo de locomoção. Aos poucos, ela vai dominando o seu corpo e, logo, é capaz de correr, saltar e pular. Já com relação à linguagem gaguejada, em sua fase considerada natural, a família, muito comumente, passa a identificar a criança como gaga, angustia-se e cobra dela uma postura linguística incompatível para aquele momento (AZEVEDO, 2006).

Friedman (1986, p. 127) descreve a gagueira como repetições, hesitações, bloqueios e temores, que são visíveis na fala. Diz que a conceituação da gagueira, precisa e clara, depende das condições internas e subjetivas do sujeito, pois ela ressalta a importância de mau-falante na origem e na manutenção da gagueira e o papel do pensamento, que "faz com que a atividade de fala se produza dentro de um contexto de antecipação de falhas na fala". Nessa situação (id., 1994), a criança se encontra em um paradoxo, pois ela precisa falar para se comunicar, mas não pode falar do seu modo. Sendo assim, emerge a crença na incapacidade articulatória. Friedman $(1978$, p. 9) vê "a causa da manifestação da gagueira não no indivíduo, mas no processo de suas relações com o outro".

Segundo Azevedo (2000), pensar a origem da gagueira seria analisar a forma como o adulto interpreta a fala da criança. Neste caso, é comum um discurso autoritário, como: Fale direito! Respire fundo! Este comportamento conduz a criança a pensar que há um erro em qualquer lugar do seu corpo. Sendo assim, quando a criança fala, ela tem como modelo a fala do outro e busca sempre assemelhar-se a ele. Este outro pode julgálo como sujeito gaguejante, o que pode provocar na criança um receio em falar e a utilização de estratégias variadas, deslocando a tensão do ato da fala para outro órgão do corpo e podendo às vezes substituir por palavras que ela considera mais fáceis. Ao perceber a diferença com o outro, o sujeito falante pode passar a sujeito-gago.

O trabalho de Mestrado e de Doutorado de Azevedo $(2000 ; 2006)$ procura estudar a gagueira sob o ponto de vista discursivo. O percurso se deu da clínica para a teoria. Primeiramente, a autora tentou compreender essa patologia a partir do funcionamento discursivo de sujeitos-gagos. Após, analisou o discurso de mães de crianças ditas gagas e de oito sujeitos-gagos, durante o atendimento fonoaudiológico.

Diante de extensa discussão sobre o lugar da gagueira, Azevedo (2000; 2006) salienta que a gagueira está situada em um espaço diferente do que foi proposto por outros pesquisadores da área. A autora afirma que a gagueira não está no sujeito, nem no ouvinte, mas nesse espaço intervalar, no seu discurso. A maioria dos sujeitos-gagos acha que a gagueira está neles próprios, na língua, no telefone, no ouvinte. O sujeito materializa sua gagueira a um objeto ou a um determinado ouvinte.

A escolha pela abordagem da Análise do Discurso de linha francesa (AD) se deve ao trabalho com a formação social e ideológica, o que nos permite entender o normal/patológico que atravessa a constituição do sujeito-gago e o discurso fonoaudiológico. Outro ponto também importante é que a $\mathrm{AD}$ compreende uma visão psicanalítica do sujeito, onde procuramos estudar a constituição do sujeito-gago.

Para Orlandi (1987), a Análise do Discurso é uma des-disciplina, uma vez que é articulada em três regiões do conhecimento científico: o Materialismo Histórico (compreendendo a teoria da ideologia), a Linguística e a teoria do discurso, atravessada por uma teoria da subjetividade, de natureza psicanalítica. Sendo assim, as regiões seriam: (i) o Materialismo Histórico; (ii) a Linguística, ampliada e constituída pela afirmação da opacidade da linguagem, tem como objeto próprio, a língua que, por sua vez, tem sua ordem própria; e, como terceira região, (iii) a Psicanálise, com a interpelação da noção de indivíduo para a de sujeito, constituindo-se na relação com o 
simbólico. A justificativa para a modificação de filiação teórica da $\mathrm{AD}$, entretanto, não está determinada em nenhuma das obras da autora.

Um conceito importante para a $\mathrm{AD}$ é a posição do locutor. $\mathrm{O}$ locutor experimenta o lugar do seu ouvinte pela antecipação, a partir do seu próprio lugar: é a maneira como o locutor concebe as representações de seu interlocutor e vice-versa. A antecipação do que o outro vai pensar é constitutiva do discurso, ao nível das formações imaginárias (ORLANDI, 1987).

Outro conceito importante para a concepção do discurso é o silenciamento. Esse conceito significa que, ao dizer, o sujeito não diz, ou diz outros sentidos. O dizer é interditado e, quando isto acontece, constituem-se discursos autoritários, onde não há reversibilidade. É negada ao sujeito a ocupação de diferentes posições, permanecendo estanque em um lugar, produzindo sentidos não proibidos (ORLANDI, 1993).

Levando em consideração o sujeito e a sua linguagem, na Análise do Discurso, Orlandi (2000) acredita que a forma que o sujeito falará dependerá da reação que irá produzir em seu ouvinte. Scarpa (1995), ao estudar a fluência e a disfluência no sujeito, relata que ambas dependem da relação do sujeito com a língua. A autora afirma que o sujeito fluente é uma abstração, já que na sua própria constituição a linguagem tem suas falhas.

Vendo a gagueira sob outro olhar, existem projetos de pesquisas, executados por grupos fortes, com grandes investimentos financeiros, que procuram identificar trações que justifiquem o aparecimento desse distúrbio. Dois grandes grupos se distinguem nas pesquisas atuais: os que através de técnicas de neuroimagem procuram observar diferenças na atuação cerebral em gagos e não gagos e os que procuram marcas genéticas correlacionadas ao aparecimento da gagueira. Os pesquisadores que estudam a ativação cerebral apontam diferenças entre gagos e não gagos, que se referem principalmente ao planejamento de execução de áreas motoras da fala. Há a informação de que em ambos os grupos, as mesmas áreas são ativadas e a diferença está na intensidade dessa ativação. Porém, uma questão ainda permanece: se o gago já traz consigo uma disfunção que se evidencia na função cerebral ou se a gagueira imprimiu essa marca no cérebro do gago. Com relação à pesquisa genética, existem avanços importantes, mas também não conclusivos. O cromossomo 12 está sendo investigado e os pesquisadores buscam conhecer o seu código genético e como ele age em pessoas gagas e não gagas (MEIRA, 2006).

Em seus estudos, Azevedo $(2000 ; 2006)$ relaciona vários pontos de vista de sujeitos-gagos como: quando o sujeito se acha incapaz de produzir certos fonemas, atribuindo de antemão a certeza do erro; ou quando a gagueira estaria no objeto que serve de intermediação (telefone, livro), ou ainda quando a gagueira está no outro, o sujeito falante se coloca na posição de sujeito-gago ao falar com um certo ouvinte. A autora afirma existir certo desencontro sobre onde estaria a gagueira, se no funcionamento da linguagem ou sob o ponto de vista do sujeito-gago. Durante seu discurso, o sujeito-gago antecipa a reação do outro, que para ele tem por objetivo apontar seus erros, reafirmando sempre a sua gagueira. A doença não está no sujeito, mas na sua relação discursiva com o outro. O sujeito-gago utiliza estratégias defensivas de evitação ou adiantamento da gagueira, substitui palavras, repete, bloqueia sons, bate o pé, tenta desviar o discurso. Azevedo observa também que no discurso do sujeitogago, há uma desarmonia entre a língua e a fala. O sujeito é submetido à língua, na medida em que se autodenomina incapaz de produzir determinados significantes. $\mathrm{O}$ sujeito-gago prioriza a língua (os fonemas, as palavras), perdendo a posição de falante. 
O sujeito-gago, ou aquele que se vê como gago, percebe a gagueira bem antes de ela acontecer, prevendo o seu erro e, quando ocorrem os bloqueios, repetições ou prolongamentos de sons, não é nenhuma novidade, porque já sabia de tudo. Com isso, ele passa a prever novos erros e a acrescentar outras palavras e sons a uma interminável lista de ditos não mais utilizáveis, ou sons/vocábulos proibidos. Diante disso, procuramos compreender a gagueira e a terapia fonoaudiológica para o sujeito-gago, que tome como ponto de partida a escuta terapêutica e se ancore no ponto de vista discursivo (AZEVEDO, 2006).

Sob essa perspectiva, a gagueira pode ser compreendida como um distúrbio linguístico-discursivo, apresentando como características, repetições de sons, sílabas, palavra ou frases, hesitações, prolongamentos de fonemas e/ou bloqueios tensos de sons.

De acordo com Friedman (2001), normalmente não prestamos atenção a como conseguimos falar, pois a fala é um ato espontâneo e automático. Falar é criar um movimento, e a produção de sons e palavras nos move a inúmeras direções. Não é preciso ser gago para gaguejar, nem gaguejar para ser gago. A gagueira, entendida sob esse prisma, se transforma em um acidente do gesto articulatório impreciso, que ocorre em uma tensão muscular. Isto abre uma brecha entre gaguejar e ser gago. Transformar um ato espontâneo em voluntário requer grande esforço para quem o tenta. $\mathrm{O}$ fato de um falante se reconhecer como diferente, como é o caso do gago, não o impede de se situar em um grupo nem o remete à impossibilidade de se comunicar. A gagueira é um tipo de comunicação possível que só aparece como diferença nas relações, mas que pode se tornar crônico e recorrente. Se o gago está na linguagem atrasando às vezes sua fala, isso não o exclui do mundo dos que se comunicam e se relacionam.

Para Van Riper (apud Friedman, 1986), a maior parte de sua análise da gagueira, ocorre em torno das relações interpessoais e do processo de aprendizagem. $\mathrm{O}$ autor relata, por exemplo, que quando sozinho, falando com crianças, animais, cantando, o gago geralmente não gagueja, apresentando assim, a integridade fono-articulatória. Descreve também que as diversas estratégias que o gago usa para evitar a gagueira, continuam a gerá-la.

Friedman (2001) afirma que o gago é uma pessoa que sofre, porque percebe que, pela sua forma de falar, é rejeitado pelos demais. Encontra-se entre o desejo de falar, de expressar pensamentos, sentimentos e o temor de fazê-lo, devido às consequências negativas que sua gagueira lhe acarreta. Ele tenta ocultá-la e, com isso, vive num estado permanente de ansiedade e angústia. Pela sua interação com o outro, o adulto gago tem sua imagem muito deteriorada, prefere a solidão e o isolamento.

Da mesma maneira que existem muitas idéias sobre a etiologia da gagueira, existe também uma dúvida sobre a terapia e os métodos de tratamento a serem usados. Um dos métodos mais usados é o de Van Riper cuja terapia é de ensinar o gago a gaguejar fluentemente. Nesse caso, seria uma terapia eclética, adotando um pouco de cada método existente. $\mathrm{O}$ autor propõe nesse método ensinar o paciente a ver de outra maneira sua gagueira, pois para ele a gagueira não é curável e sim modificável.

Em seu método terapêutico, Van Riper (apud Friedman, 1986) utiliza-se de sequências terapêuticas, $\mathrm{Na}$ fase de identificação, o paciente aprende a analisar o seu tipo de gagueira. Na fase de dessensibilização, o paciente aprende a diminuir sua ansiedade em relação à fala, ou seja, o paciente gago aprende a lidar com a disfluência. $\mathrm{Na}$ fase de modificação, ensina-se ao paciente uma maneira menos anormal de gaguejar; 
e a fase de estabilização é a de consolidar o que foi aprendido, isto é, quando o paciente deve automatizar sua fluência

Friedman (2001) propõe uma abordagem terapêutica que recupera a história de vida do sujeito, quanto aos aspectos de fala e linguagem, desmistificando a imagem de mau-falante formada na primeira infância. Para tanto, ela busca a construção do personagem bom falante utilizando técnicas proprioceptivas, que levem o sujeito a perceber sua integridade articulatória, a aceitação do silêncio na fala, a compreensão da dialética subjetividade/objetividade de modo de produção da gagueira, além de exercícios de atividades de fala, para que a gagueira possa ser entendida como natural e não mais como sofrimento.

No entanto, acredita-se que a terapia com sujeitos-gagos caminha em direção contrária à da exposta acima, ou seja, indica que a gagueira não se encontra naquele que fala, assim como não é um problema do interlocutor, mas relaciona-se às condições de produção e ao espaço do discurso, em uma relação necessária com a exterioridade (AZEVEDO, 2006).

Há um desencontro entre onde está a gagueira sob o ponto de vista do funcionamento da linguagem e sob o ponto de vista do sujeito-gago. No discurso do sujeito-gago, ele retira do outro (interlocutor) a sua função de intérprete do discurso, assumindo a visão do outro como a de alguém que é intérprete dele enquanto sujeitogago (AZEVEDO, 2006). Orlandi (2001) afirma que na antecipação o locutor experimenta o lugar de seu ouvinte, a partir de seu próprio lugar, ou seja, ela é constitutiva do discurso, no nível das formações imaginárias e significa a maneira como o locutor representa o seu interlocutor e vice-versa.

Sendo assim, o interlocutor deixa de representar a pessoa com quem o sujeitogago conversa e passa a assumir o lugar daquele que aponta seus erros, julgando sempre como gago. Porém, isto é algo que ele antecipa do outro, o que, nem sempre, está no outro. No entanto, acreditamos que a gagueira não é constituída por uma posição em relação $a$, e sim porque o sujeito-gago se vê sempre como gago (AZEVEDO, 2006).

O interesse em considerar a gagueira sob um olhar discursivo é explicado porque a linguagem representa também o sujeito social, sujeito da ideologia. Sendo assim, diante da análise do discurso de sujeitos-gagos, pretende-se apontar para um funcionamento peculiar da linguagem. Apesar de se trabalhar na Fonoaudiologia com o funcionamento da linguagem, precisa-se considerar que essa linguagem constitui e é constituída pelo sujeito (AZEVEDO, 2006).

Acreditamos que a terapia fonoaudiológica deve ressignificar a concepção de fluência, procurando compreender a disfluência como constituinte do sujeito/linguagem. É necessário esclarecer o conceito de disfluência, visto que a finalização do processo terapêutico tem relação com a noção de fluência/disfluência. Nesta concepção, a gagueira é considerada um distúrbio da linguagem, relacionada às condições de produção do discurso, caracterizado pela previsão do erro. A terapia com o sujeito-gago não é vista como um procedimento de estímulo-resposta gerador de controle de fala, mas como um processo, onde se considera a história do sujeito, de sua construção e elaboração linguístico-discursiva. Alguns conteúdos são privilegiados nesse enfoque, como a determinação do espaço discursivo como o lugar da gagueira, a ressignificação da concepção de fluência e disfluência, o reconhecimento e a identificação e análise das condições de produção do discurso, das situações de previsão e certeza do erro, bem como das estratégias discursivas e não-discursivas usadas com o intuito de adiar ou evitar a gagueira (AZEVEDO, 2006). 
Azevedo (2006) assinala que a entrevista inicial fonoaudiológica com sujeitos adultos e adolescentes pode ser realizada com aquele que procura a terapia, devendo ser escutado de forma singular. $\mathrm{Na}$ perspectiva discursiva, pode-se apontar como possibilidades terapêuticas a determinação do espaço discursivo como o lugar da gagueira, levando o sujeito a identificar as condições de produção do discurso gaguejado e do discurso fluente. A alta terapêutica nunca é oferecida unilateralmente pelo terapeuta, mas compreendida como uma demanda do sujeito e bastante trabalhada no processo. A alta é uma possibilidade de desvinculação com o processo terapêutico. Essa desvinculação acontece quando o sujeito adquire nova formação discursiva sobre a gagueira: compreender que as situações em que se mostrava como gago podem fazê-lo sujeito não-gago.

\section{CAMINHOS METODOLÓGICOS PARA ENXERGAR O SUJEITO-GAGO}

A pesquisa foi conduzida através de uma análise quantitativa e qualitativa de pastas de quarenta pacientes diagnosticados como portadores de gagueira, pertencentes à Clínica Manoel de Freitas Limeira da UNICAP (Setor de Fonoaudiologia). Os pacientes selecionados deveriam atender aos seguintes critérios: (i) apresentar diagnóstico de gagueira; (ii) situar-se na faixa etária de até 60 anos, evitando, com isso, degenerações neurológicas decorrentes da senilidade; (iii) aceitarem livremente a participação na pesquisa; e (iv) assinarem o termo de livre consentimento e aceitação.

Foram colhidos desses sujeitos dados relevantes para nossa pesquisa e feita a análise do registro de entrevista inicial, o que chamamos de anamnese. Dessa forma, foram analisadas as entrevistas iniciais ou anamneses fonoaudiológicas. Os dados coletados, através da entrevista inicial, foram discutidos e os resultados obtidos, para melhor análise dos dados, foram enquadrados nas seguintes categorias: autoimagem, contato visual, ativação emocional, estratégias e etiologia da gagueira.

\section{O ESPELHO DA GAGUEIRA: O DISCURSO DE SUJEITOS-GAGOS}

Notamos que grande parte desses sujeitos apresenta características em comum, o que nos levou a dividi-las em categorias: etiologia da gagueira, auto-imagem, estratégias, alteração no contato visual e ativação emocional. É importante salientar que em alguns casos poderá haver repetições de sujeitos em mais de uma categoria. A partir do que foi analisado nessas pastas, encontramos os seguintes dados:

\section{Categoria I - Etiologia da Gagueira}

Esta categoria foi destacada a partir das queixas dos sujeitos-gagos a respeito da causa do problema, conforme visto que as anamneses fonoaudiológicas são realizadas a partir da associação livre ${ }^{1}$ dos pacientes que marcam, nas falas, o que é importante em relação à queixa e à demanda.

\footnotetext{
1 Associação livre, segundo Lacan (1978), é a técnica utilizada na psicanálise necessária ao encaminhamento do processo analítico. Desta forma, o sujeito fala livremente, a partir de associações próprias e o analista interpreta o seu dizer.
} 
De acordo com gráfico abaixo, verificamos que não há diferenças significativas, pois grande parte dos pesquisados não apresentaram registros sobre essa categoria no prontuário, o que torna difícil realizar a interpretação desses dados. Porém, das repostas que obtivemos, a gagueira teria sua possível causa relacionada ao uso de discursos autoritários em $17,5 \%$ das respostas. A hipótese da hereditariedade viria em segundo lugar com 15\%; e, em terceiro e último, a gagueira teria sua causa devido a possíveis traumas que a criança poderia ter sofrido em sua infância com $7,5 \%$.

\section{Gráfico 1- Etiologia da Gagueira}

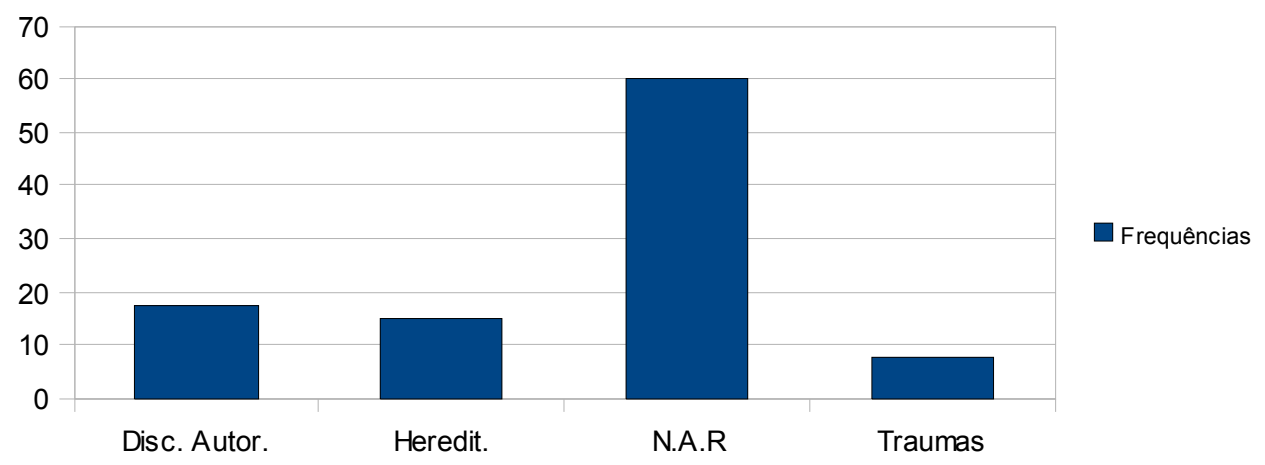

Disc. Aut.: Discurso autoritário

Heredit.: Hereditariedade

Traumas: Traumas

N.A.R.: Não apresenta registros sobre esta categoria no prontuário

Barbosa (1998, p. 11) afirma que frequentemente os pais a procuraram com a queixa de gagueira e traz consigo algo que possa estar relacionado com a causa da gagueira de seus filhos ("acho que meu filho é gago porque andava muito com o primo que também era") ou buscam algum fato que tenha acontecido anteriormente quando a criança começou a manifestar os primeiros sintomas da gagueira (IRWIN, 1993). Desse modo, na categoria I, procuramos analisar a possível causa da gagueira. Foram analisadas quarenta pastas de pacientes gagos. Desses quarenta pacientes, dezesseis relataram a possível causa da gagueira. Os outros vinte e quatro não pronunciaram informações a esse respeito. Sete dos dezesseis pacientes apresentam como possível causa da gagueira a forma como o adulto interpreta a fala da criança. Neste caso, é comum o uso do discurso autoritário, como: Respire Fundo! Fale direito! Assim, esse comportamento leva a criança a pensar que há um erro em sua fala e que esta não tem a capacidade articulatória de assemelhar-se ao ouvinte (AZEVEDO, 2006).

Friedman (1986) considera como origem da gagueira o momento em que os pais apontam essa disfluência. Assim (idem, 1978), a causa da manifestação da gagueira não está no indivíduo, mas na sua relação com o outro. Em contrapartida, Azevedo (2000) considera que a gagueira não está nem no sujeito, nem no ouvinte, mas nesse espaço, no seu discurso.

O nosso ponto de vista sobre a questão etiológica da gagueira é baseado no estudo de Azevedo (2000, p. 115; 2006), que analisa o discurso de pais de crianças ditas gagas. Ficou comprovada a existência de discurso autoritário, "porque não permitem a 
reversibilidade discursiva, no que tange à gagueira", uma vez que o mediador que a criança vai seguir para o seu desenvolvimento da linguagem age de forma equivocada em relação à gagueira.

Segundo Azevedo (2000), durante o período de desenvolvimento da linguagem, a criança encontra dificuldades naturais para expressar o que quer, devido ao pouco espaço de tempo, e até mesmo para a seleção de palavras, o que poderá causar prolongamentos, repetições ou hesitações.

\section{Categoria II - Autoimagem}

Esta categoria procura analisar a imagem que o sujeito-gago tem de si em relação à sociedade.

\section{Gráfico 2 - Autoimagem}

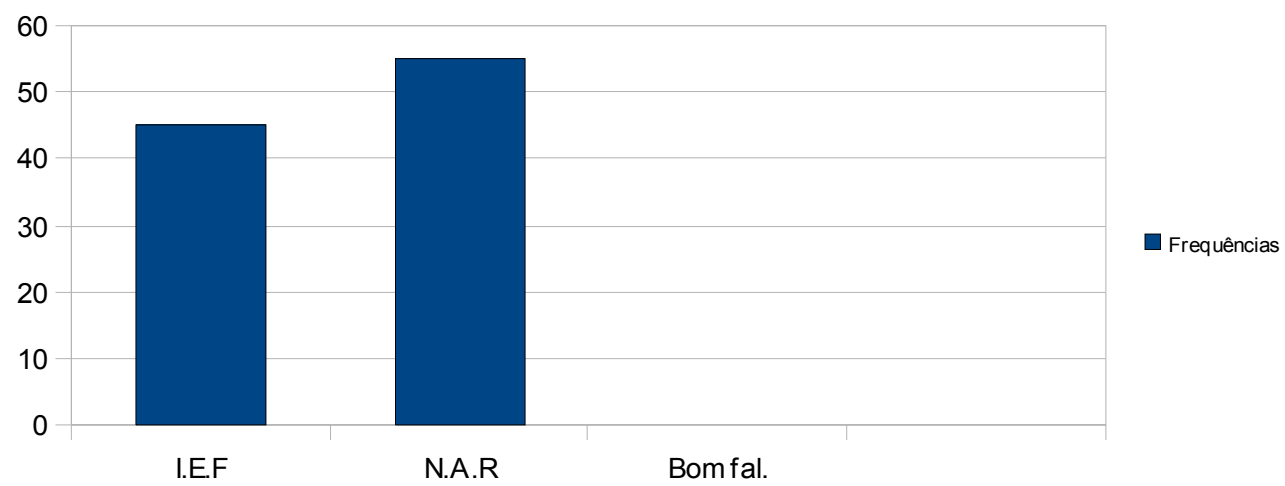

I.E.F: imagem estigmatizada de falante

N.A.R.: Não apresenta registros sobre esta categoria no prontuário Bom fal.: bom falante

Podemos verificar no gráfico que a maior parte dos pesquisados não apresentaram registros sobre essa categoria em seus prontuários, tendo como resposta $55 \%$. Porém, aqueles que responderam todas as respostas foram aqueles que apresentam a imagem estigmatizada de falante, tendo vergonha, medo de se comunicar com as pessoas, devido às reações delas; por isso, preferiam silenciar. A imagem do sujeitogago estigmatizada de falante teve como resposta $45 \%$.

A gagueira causa grande impacto sobre a identidade e os relacionamentos pessoais dos gagos. Muitas pessoas que gaguejam, sofrem com isso, sentem medo, vergonha, impotência e assim tentam disfarçar ou esconder sua gagueira (STEWART apud FRIEDMAN, 2001). Foram selecionados quarenta sujeitos, dentre os quais, dezoito apresentam imagem estigmatizada de falante. Vinte e dois sujeitos não opinaram nesta categoria e nenhum pesquisado relatou não apresentar imagem de maufalante.

O sujeito-gago se sente subjugado pelo preconceito social. Ele tenta resgatar a fluência de sua fala como uma potência, um meio de se autoafirmar, um modo de 
exercitar sua criatividade, de expressar a sua individualidade e de alcançar uma posição dentro da sociedade (BARBOSA, 1998).

Segundo Beraldo (2003), a partir da manifestação da gagueira, o sujeito-gago pode ter tipos de comportamento que podem tipificar a sua fala, tendo idéias como: devo falar bem, sou péssimo falante, não devo gaguejar.

A ideologia do bem falar manifestou-se pela não aceitação do padrão de fala espontâneo desses sujeitos, desde que eles se entendem por gente, segundo as palavras de um deles. $\mathrm{O}$ que nos permitiu constatar que a gagueira se articula a partir de relações de comunicação que, sistematicamente, colocam a fala numa situação paradoxal (FRIEDMAN, 1994).

\section{Categoria III: Ativação Emocional}

Nesta categoria III, procuramos identificar se existe relação entre a gagueira e a ativação emocional. Dos 40 pacientes pesquisados, obtivemos como resultado que 16 sujeitos notam que a gagueira piora em situações que causam estresse. Ainda relatam que quando ficam nervosos a gagueira também piora e apresentam tensão. Vinte e dois sujeitos não apresentaram registros sobre esta categoria e dois relataram que sua gagueira não piora em estados de estresse e não apresentam tensão.

\section{Gráfico 3 - Ativação emocional}

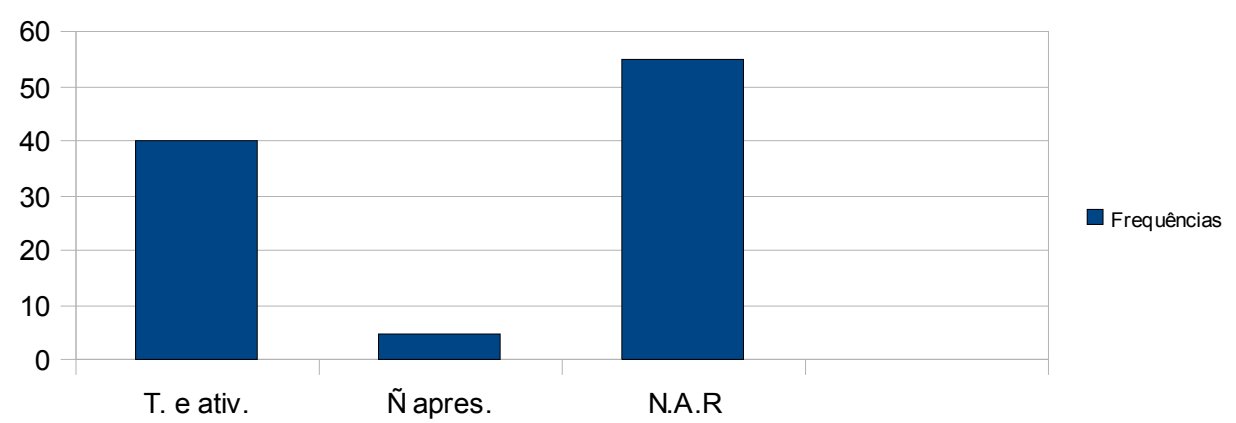

T. e ativ.: Apresenta ativação emocional

Ñ apres.: Não apresenta mudança em situações de nervosismo

N.A.R: Não apresenta registros sobre esta categoria no prontuário

De acordo com o gráfico acima, $40 \%$ dos pacientes pesquisados revelam apresentar piora significante da gagueira em situações que causam estresse e os deixam nervosos; $55 \%$ dos pacientes não se referiram a esse aspecto; e apenas $5 \%$ relataram não identificar mudanças em sua gagueira em momentos de maior estresse e nervosismo, também relatando não apresentar tensão.

Segundo Van Riper (apud BERALDO, 2003), os sintomas da gagueira apresentam vários níveis de tensão. Meira (1986) diz que a gagueira está rodeada por 
tensões e apresenta as principais tensões como: tensão oral, tensão cervical e tensão diafragmática.

Para Friedman (2001), qualquer falante pode apresentar gagueira natural, podendo gaguejar no contexto de sua fala, sendo assim, não existe $100 \%$ de fluência em ninguém. $\mathrm{O}$ aparecimento da gagueira tem um motivo peculiar para cada pessoa, por exemplo, diante de um sentimento de segurança sobre o que vai ser falado, a fala tornarse mais fluente do que no contexto de ansiedade, insegurança e competição para falar.

\section{Categoria IV: Contato Visual}

A categoria IV tem como objetivo estabelecer a relação entre o contato visual do sujeito-gago e não-gago, a fim de confirmar se existe realmente alteração do contato visual do sujeito-gago. Dos quarenta sujeitos pesquisados, quatorze dizem não apresentar contato visual, oito relatam não apresentar alteração e dezoito não se referiram sobre esta categoria.

Gráfico 4 - Alteração no contato visual

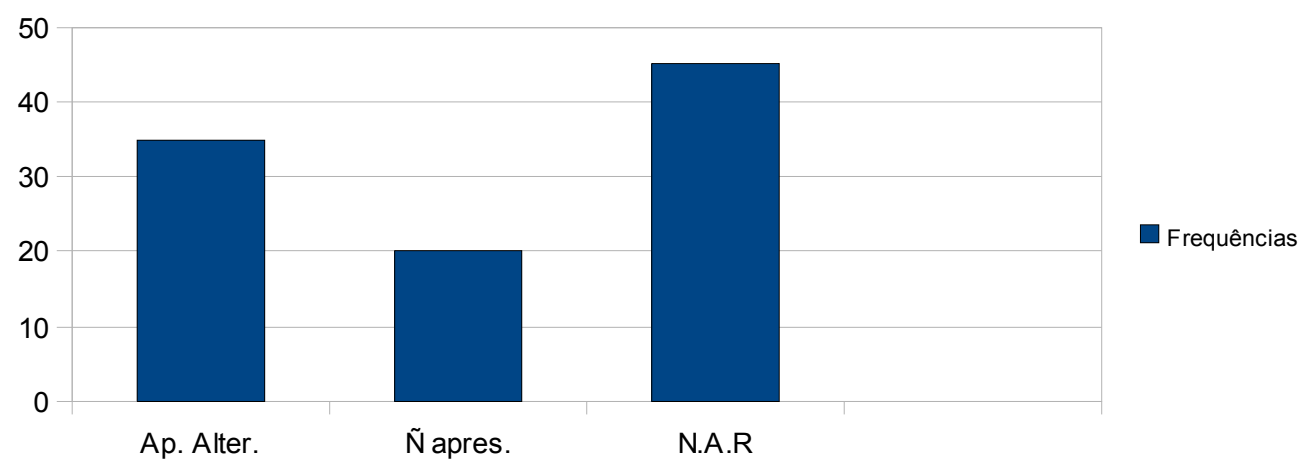

Ap. Alter.: Apresentou alteração no contato visual Ñ. Apres.: Não apresentou alteração

N.A.R: Não apresenta registros sobre esta categoria no prontuário

De acordo com o gráfico acima, 35\% dos pacientes relataram apresentar alteração no contato visual; $20 \%$ revelaram que não apresentam alteração no contato visual e $45 \%$ apresentaram registros sobre esta categoria em seus prontuários.

Segundo Van Riper (1972), uma das atitudes mais típicas do sujeito-gago é evitar o contato visual com o interlocutor. O autor relata que o sujeito-gago diz evitar o contato visual porque não aceita a sua gagueira e se envergonha dela.

\section{Categoria V: Estratégias}

$\mathrm{Na}$ categoria $\mathrm{V}$, procuramos analisar as estratégias que os sujeitos-gagos utilizam para adiar sua gagueira ou até mesmo mascará-la. Obtivemos como resultado 
que, de quarenta pacientes pesquisados, treze apresentaram estratégias defensivas de evitação da gagueira e os outros vinte e sete sujeitos não apresentaram informações sobre essa categoria em seus prontuários.

\section{Gráfico 5 - Estratégias}

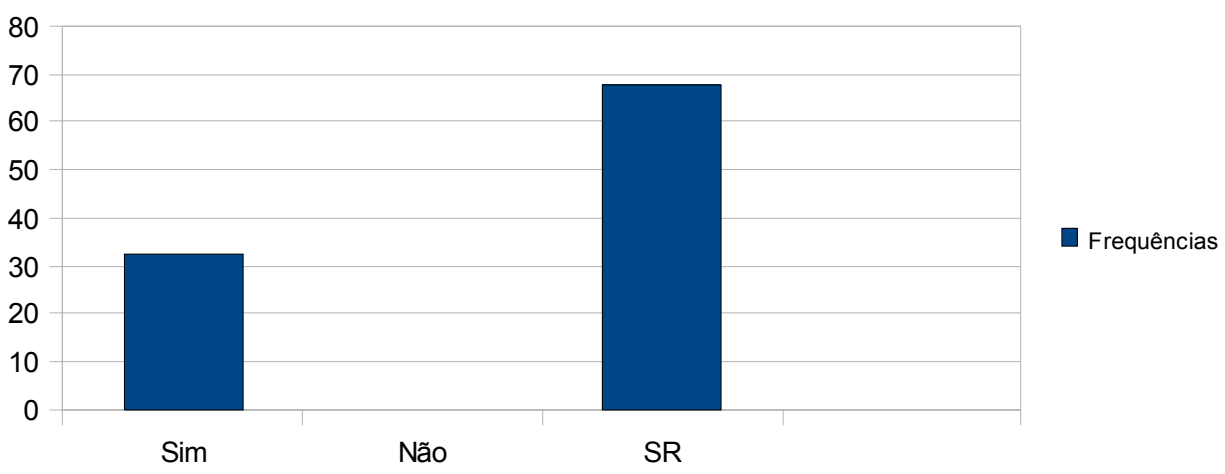

Sim: relatam utilizar estratégias

Não: relatam não utilizar estratégias

SR: Sem registros de estratégias no prontuário

Segundo Azevedo (2000; 2006), o sujeito-gago utiliza várias estratégias de defesa ou adiamento da gagueira, substitui palavras, repete, bloqueia sons, bate o pé, tenta desviar o discurso. Geralmente, a gagueira provoca aceleração das batidas cardíacas, movimentos anormais nos olhos, transpiração excessiva, irregularidade na respiração (VAN RIPER, 1972).

Diante dos resultados do gráfico, verificamos que $32,5 \%$ dos pacientes tentam de alguma maneira adiar sua gagueira. No entanto, estudando sobre a teoria da gagueira, percebemos que quanto mais o sujeito-gago tenta escondê-la, mais ela é confirmada. Friedman (1994) afirma que o sujeito-gago utiliza recursos corporais para esconder sua gagueira, no entanto, ele mostra-se mais gago, na medida em que são interpretados como características de insegurança e tensão corporal. Já $67,5 \%$ dos sujeitos pesquisados não apresentaram registros sobre esta categoria.

O sujeito-gago utiliza estratégias discursivas e não-discursivas com o intuito de adiar ou evitar o discurso gago. As estratégias discursivas são aquelas que procuram adiar ou evitar a gagueira, em que o sujeito age sobre o discurso. Encontram-se nessa categoria as substituições de palavras (palavras previstas como possivelmente gaguejadas) por outras consideradas mais simples e, portanto, mais facilmente articuladas. As estratégias não-discursivas também objetivam evitar ou adiar o discurso gaguejado, com a diferença que, nestas, há uma fuga do discursivo. O sujeito age no corpo, utilizando um artifício corporal, como piscar fortemente os olhos, bater os pés, as mãos, mexer a cabeça, sempre evitando gaguejar, ou tentando falar bem (AZEVEDO, 2006). 


\section{CONCLUSÃO}

Diante do que foi estudado sobre a gagueira, observou-se que essa tem sido discutida por diferentes concepções. Porém, chegamos ao consenso de que a gagueira é vista como uma forma de sofrimento e procuramos compreendê-la como um distúrbio discursivo, diretamente relacionado às condições de produção, em que, mesmo antes de falar, o sujeito já tem a certeza de que gaguejará.

$\mathrm{Na}$ análise de quarenta sujeitos-gagos, avaliamos sua entrevista inicial, anamnese, que foram realizadas com estagiários da clínica de Fonoaudiologia da UNICAP e pudemos identificar que a maioria dos sujeitos que chega à clínica de Fonoaudiologia da UNICAP, apresenta como queixa principal a gagueira. Procuramos investigar a história do paciente, bem como a relação que o sujeito estabelece com sua gagueira, onde obtivemos os seguintes resultados: a) relacionam a causa da gagueira à origem genética, psicossociais e orgânicas; b) relatam apresentar contato visual alterado e não aceitarem a sua gagueira; c) afirmam fazer uso de estratégias adiadoras da gagueira, usando tiques e até mesmo a substituição de palavras que julgam mais difíceis de serem pronunciadas. O sujeito-gago antevê os momentos de disfluência, tentando eliminá-los e obtendo em vez disso uma fala tensa, aumentando ainda mais sua disfluência; d) relatam perceber aumento de disfluência em situações de estresse emocional; e e) relatam também apresentar uma subjetividade marcada pela visão negativa, estigmatizada de si como falante, que se constitui a partir de relações de comunicação em que sua fala não é aceita.

O sujeito-gago é discriminado diante da sociedade, sendo sua gagueira vista como uma doença, que precisa ser curada. Sendo assim, nosso objetivo terapêutico diante da gagueira é inserir outra visão sobre a mesma, tentando desmistificar que a fala é sempre perfeita, sem deslizes. É fazer com que o gago comece a perceber em sua fala seus momentos de fluência e mudar sua autoimagem de sujeito-gago, para sujeitofluente. Existe uma ideologia do bem falar na sociedade. Sendo assim, é esperado que todas as pessoas falem bem e corretamente. Ao gaguejar, o sujeito carrega consigo a autoimagem estigmatizada de falante, formada ainda na infância, considerando um estigma social marcado. A partir dessa visão, entendemos a importância que os valores sociais e a interpretação do outro, tem para a produção da fala.

Espera-se que as entrevistas iniciais dos sujeitos-gagos contribuam para um novo olhar sobre esse discurso: uma visão que elimine sua ideologia estigmatizada de falante, de um sujeito marginalizado e discriminado, desconsiderando assim o mito existente da fala perfeita, sem deslizes, completamente fluente.

\section{REFERÊNCIAS}

AZEVEDO, Nadia Pereira da Silva Gonçalves de. Uma Análise discursiva da gagueira: trajetórias de silenciamento e alienação na língua. 2000. 126 f. Dissertação (Mestrado) Pontifícia Universidade Católica de São Paulo - PUC-SP. Curso de Mestrado em Fonoaudiologia.

- A gagueira sob a perspectiva lingüistico-discursiva: um olhar sobre a terapia. Tese de doutorado (doutorado em Letras e Lingüística). UFPB - PB, 2006. 
BARBOSA, Lucia Maria Gonzales; CHIARI, Brasília Maria. Gagueira: Etiologia, prevenção e tratamento. 1. ed. Carapicuiba (SP): Pró-Fono, 1998. 98 p.

BERALDO, H. Gagueira Severa em Adultos. Disponível em: < http://www.psicossomatica-sp.or.br/monografias3.doc>. Acesso em 20 dez. 2006.

FRIEDMAN, Silvia. Gagueira: Origem e tratamento. 2. ed. São Paulo: Summus, 1978. 143 p. : Il.

Cartas com um paciente (co-autor): Um processo de terapia para gagueira. 1. ed. São Paulo: EDUC, 1986. 71 p.

. O caso de Amadeu. In: FRIEDMAN \& CUNHA. Gagueira e

Subjetividade: possibilidades de tratamento. Porto Alegre: Artes Médicas, 2001.

IRWIN, Ann. Gagueira: Uma ajuda prática em qualquer idade. 1. ed. São Paulo: Martins Fontes, 1993. 149 p.

LACAN, J. Escritos. São Paulo: Editora Perspectiva. S.A, 1978.

MEIRA, Isis. Associação Brasileira de Gagueira. Banco de dados. Disponível em: $<$ http://www.abragagueira.org.br/2forumonline_go.asp?idForum=6>. Acesso em 15 set. 2006.

ORLANDI, E. A linguagem e seu funcionamento: as formas do discurso. Campinas, SP: Pontes, 1987.

. As formas do silêncio: no movimento dos sentidos. Campinas, SP: Editora da UNICAMP, 1993.

. Análise de Discurso: princípios e procedimentos. Campinas, SP: Pontes, 2000.

Pontes, 2001.

Discurso e texto: formulação e circulação dos sentidos. Campinas, SP:

SCARPA, E. M. Sobre o sujeito fluente. Cad. de Estudos Lingüísticos, Campinas, v.29, p.163-184, Jul./Dez., 1995.

VAN RIPER, C. Speech Correction: principles and methods. 5 ed., Englewood Cliffs, New Jersey: Prentice-Hall, 1972. 